\title{
Productive resources in students' ideas about energy: An alternative analysis of Watts' original interview transcripts
}

\author{
Benedikt W. Harrer, ${ }^{1, *}$ Virginia J. Flood, ${ }^{2}$ and Michael C. Wittmann ${ }^{1,2}$ \\ ${ }^{1}$ Department of Physics and Astronomy, University of Maine, Orono, Maine 04469, USA \\ ${ }^{2}$ Center for Research in STEM Education, University of Maine, Orono, Maine 04469, USA
}

(Received 31 May 2013; published 10 September 2013)

\begin{abstract}
For over 30 years, researchers have investigated students' ideas about energy with the intent of reforming instructional practice. In this pursuit, Watts contributed an influential study with his 1983 paper "Some alternative views of energy" [Phys. Educ. 18, 213 (1983)]. Watts' "alternative frameworks" continue to be used for categorizing students' non-normative ideas about energy. Using a resources framework, we propose an alternate analysis of student responses from Watts' interviews. In our analysis, we show how students' activated resources about energy are disciplinarily productive. We suggest that fostering seeds of scientific understandings in students' ideas about energy may play an important role in their development of scientific literacy.
\end{abstract}

DOI: 10.1103/PhysRevSTPER.9.023101

PACS numbers: 01.40.Fk, 01.40.ek

\section{INTRODUCTION}

Energy plays a central role in scientific explanations of physical and biological phenomena, and figures prominently in current sociopolitical discussions. A versatile understanding of energy is desirable for students as they develop scientific literacy. Since the 1970s, researchers have investigated students' ideas about energy with the goal of reforming instructional practice in the topic.

A substantial portion of this research has used interviews about instances [1] to elicit and characterize students' energy conceptions. The most cited of these studies is Watts' 1983 paper "Some alternative views of energy" [2] that is based on his Ph.D. thesis [3]. Watts created categories for student responses that have been used by other researchers to compile and classify students' nonnormative ideas about energy [4].

Using a resources framework, we present an alternative analysis of Watts' interview transcript excerpts. In this analysis, we find productive seeds of scientific understandings of energy.

\section{WATTS' THEORETICAL FRAMEWORK AND METHODOLOGY}

Watts used the interviews about instances approach to investigate what he called students' "alternative frameworks" [5] of conceptualizing energy [2]. In his interviews, he presented students with up to 17 line drawings of what he had determined to be "instances" or

\footnotetext{
*benedikt.harrer@maine.edu

Published by the American Physical Society under the terms of the Creative Commons Attribution 3.0 License. Further distribution of this work must maintain attribution to the author(s) and the published article's title, journal citation, and DOI.
}

"non-instances" of the scientific energy concept. Watts defined a concept as a class of members with common features. An instance was defined as a member of the class $[3,6]$ (e.g., a Jack Russell terrier is an instance of the concept "dog").

Using these interviews, Watts intended to investigate what "well-developed" ideas students held about energy. He believed that these ideas "are part of a complex structure which provides a sensible and coherent explanation of the world" ([2], p. 213). In the interviews, Watts elicited students' reasons for deciding whether a card depicted an instance or not. After conducting 40 interviews about instances with 13-16 year-old secondary physics and general science students in the United Kingdom, Watts sorted the responses into bins. He termed these bins "frameworks" and characterized them in relation to "concepts in the network of physics" ([3], p. 1.39). Watts' work was motivated by the assumption that establishing the details of students' alternative frameworks (and therefore their ideas) is important for instructional success in the classroom.

\section{RESOURCES: A FRAMEWORK FOR INVESTIGATING PRODUCTIVE IDEAS}

We agree with Watts that it is crucial to understand students' ideas for instruction to be effective. However, our analysis of Watts' data is motivated by the assumption that identifying the appropriately activated disciplinary elements in students' ideas is necessary to guide instruction [7]. Instructors' responsiveness to students' early disciplinary ideas has been shown to foster the development of more robust scientific understandings [8-10].

The resources framework [11,12] of Hammer and his colleagues provides useful concepts for our investigation of students' productive ideas about energy. The framework conceives of the mind as a dynamic, complex system of 
cognitive elements, called "resources" [11-13]. Resources can range in grain size from small, basic elements like diSessa's phenomenological primitives, or p-prims (e.g., "closer means stronger") [14], to more complex conceptual structures like coherent theories about physical phenomena. The existence of conceptual, epistemological, procedural, metacognitive, mathematical, and other resources has been proposed and empirically validated $[12,15-17]$. We see resources as basic pieces of declarative and procedural knowledge, or bigger knowledge structures that are composed of multiple such pieces [17,18].

Watts' view that students' ideas are varied and context dependent is aligned with a resources perspective. However, a resources perspective does not assume that these ideas are stable ([3], p. 3.1) or coherent and that they need to be replaced with a unified scientific concept (or at least "moved closer to the 'accepted truth" ([3], p. 7.43) during instruction. Instead of Watts' approach of classifying students' responses into categories and describing these "discernible common conceptual frameworks that are alternative [...] to the system of public scientific meanings" ([3], p. 1.44), we use the suggested approach of Brown and Hammer of identifying productive resources that are "conceptual progenitors of expert understanding in students' intuitions" ([13], p. 145).

Learners activate resources when reasoning about physics phenomena [12]. We understand the term activation to mean the recognition of the applicability (as judged by the learner) and application of a resource to a certain situation. We propose a definition of productiveness as the appropriate activation of a resource as judged by the community of physicists (via the instructor or researcher) in a learning environment. This definition is consistent with examples in which Hammer and colleagues describe productive resources [9,19-21]. Brown and Hammer have called for more efforts to systematically identify productive resources in students' ideas [13].

When learners communicate their ideas, they provide researchers with evidence for the activation of particular resources. In this paper, we reproduce and analyze excerpts from transcripts [22] in Watts' dissertation [3] that resulted in his frequently cited paper [2]. We present analyses of three transcript excerpts and argue that they contain evidence for students' activation of resources that are of disciplinary value in the context of energy.

\section{ALTERNATIVE ANALYSIS OF STUDENTS' IDEAS}

\section{A. Energy as a metaphorical substance}

One student (student C) in Watts' study is presented with the drawing of a stick figure on an inclined plane, pushing a box (see Fig. 1). The student is asked in what ways the drawing is an instance of energy. The excerpt of the transcript of the student's answer is reproduced in transcript 1 . Watts used this excerpt to illustrate what he called the
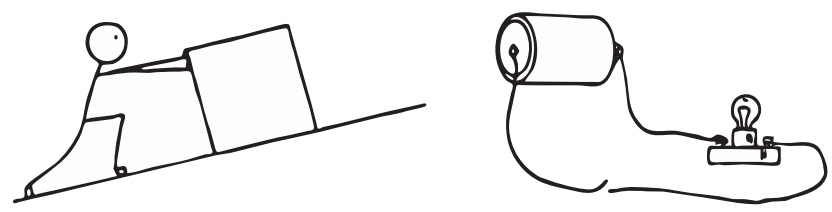

FIG. 1. Instances "Pushing a heavy box up a hill" and "A battery, bulb and switch" [2].

"Anthropo-centric/-morphic Framework." This framework served as a category for student responses that Watts interpreted as human centered, i.e., they relate to humanlike and human-caused action, view energy as a vitalistic entity only concerned with living creatures, and describe other active, but inanimate, objects in humanistic terms.

(1) I: ... someone pushing a box up a hill ... what about that one?

(2) C: ... yes I think it would /be an example of energy/ because umh. ..(10)... I think that's why we eat to .. umh... collect the energy to push things to ... umh ... kind of walk ... so I think I'd put it /as an example/ because he is a source of energy ... he pushes on the box up the hill.

(3) I: Has the box any energy?

(4) C: ... (4) ... no ... because its just a box.

Transcript 1. Extract 2, person pushing a box up a hill ([3], pp. 4.27-4.29).

Student $\mathrm{C}$ starts his justification for why the scenario contains energy with "that's why we eat to [...] collect the energy to push things [and] walk" (line 2), indicating that he believes eating food provides the human body with the necessary energy to perform physical activity. Through his statement, he claims that energy stored in an object enables physical activity or work. We use grammatical indicators, i.e., words like "collect" or "source of," to identify the use of a substance metaphor, a resource that student $\mathrm{C}$ activates when explaining the energy involvement in the scenario at hand. Energy is proposed to be a quasimaterial (substancelike) entity that can be collected (accumulated). This resource also suggests that energy can be transferred between objects. Consistent with student C's use of a substance metaphor is the description of the stick figure as a "source of energy" (line 2).

The use of a substance metaphor for energy has been described as compatible with and useful for a disciplinary understanding of energy-related phenomena. For example, substance metaphors have been suggested to be beneficial for the development of an understanding of energy as a conserved quantity [23-26]. For these reasons, substance metaphors have been established as a central feature of energy in several instructional approaches [26-28]. Describing energy with a substance metaphor is consistent with the argument of Lakoff and Johnson that all concepts, no matter how abstract, are understood through metaphors 
grounded in our bodily experience in the world [29]. Gupta et al. used this perspective to argue that experts make productive use of multiple ontologies for physical phenomena [20].

We see students' employment of multiple ontologies, and, in particular, student C's substance metaphor, as productive for the learning of energy. We also judge that student C's activation of the resource substance metaphor would be deemed appropriate from the perspective of the community of physicists, based on its acceptance by the wider community as represented by the literature cited above.

\section{B. Movement as an indicator for energy involvement}

Another student, J1, is characterizing energy in general in response to a prompt that is not specified in Watts' dissertation. We believe that the prompt was a question like "what do you think energy is?" According to Watts, the excerpt in transcript 2 illustrates his "Depository Energy Framework." He used this framework to classify responses that locate energy in certain objects, "so that [...] they all have their own internal source of energy," and that see "such energies as being intrinsically distinct and having different names" ([3], p. 4.31). Watts further claimed that students who adhere to this framework see energy as a causal agent.

(1) $\mathrm{J} 1: \ldots$ if something moves its got to have energy ... its got to be there ... its going to have energy inside it.

(2) I: do you think that everything has got energy inside it?

(3) J1: no not really... I mean I don't know if a table's got energy in it ... I suppose it has but I'm not really sure.

(4) I: you said something about moving ... what if it /an object/ moves ... what then?

(5) J1: well if it's moving ... yes ... it'll have energy inside it.

(6) I: Why do you say that?

(7) $\mathrm{J} 1: \ldots$ because I think the energy ... that if it /the object/ is still ... the energy's going to be building up inside it ... well potential energy ... and then it moves.

Transcript 2. Extract 7 ([3], pp. 4.31 and 4.32).

Student $\mathrm{J} 1$ says that if an object is moving, it must "have energy inside it" (line 1). The interviewer returns to student J1's idea about a moving object (line 4), and student J1 reveals his commitment to the idea that an object has energy if it is moving (line 5). When asked about his reasons for stating this idea (line 6), student $\mathrm{J} 1$ says that an object builds up potential energy when it is not moving, "and then it moves" (line 7).

Using the if-then structure of student J1's statements as grammatical indicators ("if [...] its got to have," line 1, and "if [...] it'll have," line 5), we argue that he views the physical displacement of objects, their "moving," as a sign of energy being present. Student J1 is therefore using an indicator to justify the presence of energy, which cannot be directly observed.

Physicists routinely identify observables for unobservable phenomena and use the former to make arguments about the latter. These observables serve as indicators for phenomena that are not directly accessible to measurement, like energy. Walz et al. [30], for example, used the fluorescence of molecules as an indicator for energy transfer. Kaper and Goedhart [31] characterized the use of the energy forms language in various physics textbooks and compiled a model of energy that is aligned with the treatment of energy in these books. In this model, different forms of energy are associated with observable, changeable properties of objects. These properties are effectively indicators for the involvement of energy.

Energy is an abstract phenomenon that cannot be measured directly. In order to recognize energy involvement and make arguments about energy in a physical scenario, measurable indicators have to be identified and used. Student J1's activation of the resource movement as an indicator for energy involvement is therefore appropriate and can be considered productive.

\section{C. "Holding electrons up" as a mechanism for energy in a light bulb}

A third student, J2, has been presented with a line drawing of a simple circuit: a battery that is connected to a bulb and a switch (see Fig. 1). The transcript excerpt in transcript 3 was used by Watts to exemplify the "Produced Energy Framework." According to this framework, energy is described as being produced by an event. Watts explained that responses in this category often treat energy as a waste product of a process.

(1) J2: .. umh well there's ... in the bulb there's a little wire and it is ... umh ... its like a resister to the electrons flowing through and ... and as the electrons flow through it's just like a force ... like a pressure ... and it sort of holds them up a bit as they come through the bulb...

(2) I: and what about energy?

(3) J2: yes ... and as the electrons flow through the bulb $\ldots$ it becomes hot and it produces energy and it gives off light

Transcript 3. Extract 21, a battery is connected to a bulb and a switch ([3], pp. 4.40 and 4.41).

Student J2 explains that there is a wire in the bulb that acts as a resistor to the electron current that is flowing through it. Within the wire, he describes a "force" or "pressure" that provides resistance and "holds [the electrons] up a bit" (line 1). When asked about energy by the interviewer, student $\mathbf{J} 2$ continues that "as the electrons 
flow through the bulb ... it becomes hot" which results in energy production and the emission of light by the bulb (line 3).

We find that student $\mathbf{J} 2$ provides a mechanistic account of how energy is produced in a light bulb in his response. Russ and colleagues have characterized mechanistic reasoning as being "nonteleological," "causal," "built from experience," and "describ[ing] underlying or relevant structure" ([32], pp. 5 and 6). Using these characteristics, they operationalized mechanistic reasoning in seven codes for recognizing signs of it in students' discourse. We use these codes (in their proposed order of increasing sophistication, italicized below) to characterize student J2's response and show that he activates the resource mechanistic reasoning.

Student $\mathrm{J} 2$ describes the target phenomenon "energy in a light bulb" when he states in line 3 that the bulb "becomes hot and it produces energy and it gives off light." He identifies setup conditions in his description of the "little wire" in the bulb that has "electrons flowing through" it (line 1). In his description, student J2 identifies several entities that "play roles in producing the phenomenon" ([32], p. 14): the wire inside the bulb, the electrons that are flowing through this wire, and the force or pressure that affects the flowing electrons. Along with these entities, he also identifies relevant activities that the entities are engaged in. The electrons are "flowing through" the wire, the force or pressure "holds them up a bit" (line 1).

Furthermore, student $\mathbf{J} 2$ identifies certain properties of entities. He characterizes the wire as "little" and being "like a resister [sic]" (line 1), and the bulb as "becom[ing] hot" (line 3). Student J2 also identifies the organization of entities in his description of the setup conditions (see above): the little wire is within the bulb, the electrons are flowing inside the wire (line 1), and therefore through the bulb (line 3).

Lastly, student J2's reasoning shows evidence of chaining, a description of the causal structure of the mechanism. In line 3, he specifies that "as the electrons flow through the bulb ... it becomes hot and it produces energy and it gives off light": The flow of the electrons through the wire and the force or pressure "holding them up a bit" causes the bulb to become hot and give off light, both of which involve energy. Although student J2's explanation is missing key information about how energy gets into the bulb or what it means that the bulb "produces energy," his explanation shows a high level of sophisticated mechanistic reasoning.

Mechanistic reasoning has been found to be at the core of scientific practice in the science, technology, engineering, and mathematics disciplines [32]. Hammer argued that "the development of a sense of mechanism should be a valuable aspect of scientific inquiry" ([33], p. 422). The pursuit of causal-mechanistic explanations of physical phenomena has been identified as a crosscutting concept of science that is necessary for the development of scientific literacy [34]. Therefore, we argue that student $\mathbf{J} 2$ productively activated the resource mechanistic reasoning to account for a light bulb's emission of energy.

\section{IMPORTANCE OF RECOGNIZING DISCIPLINARY PROGENITORS}

We have analyzed transcripts from Watts' interviews about instances to reveal a dimension of students' ideas about energy that is distinct from Watts' original descriptions. Watts classified students' responses, which he viewed as emerging from their use of stable and coherent conceptions about energy, into common "alternative frameworks." His work influenced other researchers who continue to use the categories in their pursuit of cataloging students' non-normative ideas about energy. In our analysis, we enlisted a resources framework to find evidence of productive and disciplinary features of these responses.

In this paper, we demonstrated how detailed analyses of students' responses reveal the activation of resources. We found evidence for students' use of a substance metaphor for energy, the identification of an object's movement as an indicator for energy involvement and mechanistic reasoning about energy in a light bulb. Furthermore, we proposed an operational definition of productiveness and illustrated how it can be used to evaluate students' activated resources as productive from a disciplinary point of view.

We suggest it is important to recognize disciplinary progenitors in students' ideas and foster them to help students develop scientific understandings. By showing that students activate a wealth of resources while reasoning about energy in various physical scenarios, we seek to contribute to the systematic identification and description of productive resources for energy. Finding the valuable elements of students' ideas provides rich opportunities for exploration and warrants further investigation in the physics education research community. Additionally, we hope that this work will motivate future research into teachers' praxis of responding to students' productive resources to foster learning.

\section{ACKNOWLEDGMENTS}

We thank the librarians of The British Library and EThOS for tracking down and supplying a digital copy of Watts' Ph.D. thesis, and Rachel E. Scherr as well as the participants in the FFPER 2013 graduate student symposium for reviewing earlier versions of this manuscript. This material is based on work supported by the National Science Foundation under Grants No. DUE 0962805, No. DRL 1222580, and No. DRL 0822342. 
[1] Roger J. Osborne and John K. Gilbert, A technique for exploring students' views of the world, Phys. Educ. 15, 376 (1980).

[2] D. Michael Watts, Some alternative views of energy, Phys. Educ. 18, 213 (1983).

[3] D. Michael Watts, Ph.D. thesis, University of Surrey, 1983.

[4] See, e.g., Joan Bliss and Jon Ogborn, Children's choices of uses of energy, Eur. J. Sci. Educ. 7, 195 (1985); Ricardo Trumper, Being constructive: An alternative approach to the teaching of the energy concept-Part one, Int. J. Sci. Educ. 12, 343 (1990); Paul Logman, Wolter Kaper, and Ton Ellermeijer, Frameworks for talking about energyMutually exclusive?, in Proceedings of the GIREP-EPEC \& PHEC 2009 International Conference on Physics Community and Cooperation (Lulu/The Centre for Interdisciplinary Science, Leicester, 2010), p. 76.

[5] Rosalind Driver and Jack Easley, Pupils and paradigms: A review of literature related to the concept development in adolescent science students, Stud. Sci. Educ. 5, 61 (1978).

[6] Roger J. Osborne and John K. Gilbert, A method for investigating concept understanding in science, Eur. J. Sci. Educ. 2, 311 (1980).

[7] John P. Smith, Andrea A. diSessa, and Jeremy Roschelle, Misconceptions reconceived: A constructivist analysis of knowledge in transition, J. Learn. Sci. 3, 115 (1994).

[8] Janet E. Coffey, David Hammer, Daniel M. Levin, and Terrance Grant, The missing disciplinary substance of formative assessment, J. Res. Sci. Teach. 48, 1109 (2011).

[9] David Hammer, Fred Goldberg, and Sharon Fargason, Responsive teaching and the beginnings of energy in a third grade classroom, Rev. Sci. Math. ICT Educ. 6, 51 (2012) [http://xantho.lis.upatras.gr/pasithee/index.php/ review/article/view/1694/1626].

[10] April C. Maskiewicz and Victoria A. Winters, Understanding the co-construction of inquiry practices: A case study of a responsive teaching environment, J. Res. Sci. Teach. 49, 429 (2012).

[11] David Hammer, Student resources for learning introductory physics, Am. J. Phys. 68, S52 (2000).

[12] David Hammer, Andrew Elby, Rachel E. Scherr, and Edward F. Redish, in Transfer of Learning: Research and Perspectives, edited by Jose Mestre (Information Age Publishing, Greenwich, CT, 2005), pp. 89-120.

[13] David E. Brown and David Hammer, in International Handbook of Research on Conceptual Change, edited by Stella Vosniadou (Routledge, New York, 2008), 1st ed., Chap. 6, pp. 127-154.

[14] Andrea A. diSessa, Toward an epistemology of physics, Cognit. Instr. 10, 105 (1993).

[15] David Hammer and Andrew Elby, in Personal Epistemology: The Psychology of Beliefs, edited by Barbara K. Hofer and Paul R. Pintrich (Lawrence Erlbaum Associates, Mahwah, NJ, 2002), Chap. 9, pp. 169-190.

[16] Katrina E. Black and Michael C. Wittmann, Epistemic games in integration: Modeling resource choice, AIP Conf. Proc. 951, 53 (2007).

[17] Jonathan Tuminaro and Edward F. Redish, Elements of a cognitive model of physics problem solving:
Epistemic games, Phys. Rev. ST Phys. Educ. Res. 3, 020101 (2007).

[18] Michael C. Wittmann, Using resource graphs to represent conceptual change, Phys. Rev. ST Phys. Educ. Res. 2, 020105 (2006).

[19] Elizabeth Gire, Corinne Manogue, Charles Henderson, Mel Sabella, and Leon Hsu, Resources students use to understand quantum mechanical operators, AIP Conf. Proc. 1064, 115 (2008).

[20] Ayush Gupta, David Hammer, and Edward F. Redish, The case for dynamic models of learners' ontologies in physics, J. Learn. Sci. 19, 285 (2010).

[21] David Hammer, Ayush Gupta, and Edward F. Redish, On static and dynamic intuitive ontologies, J. Learn. Sci. 20, 163 (2011).

[22] Watts' transcript conventions are not exhaustively defined; we interpret them as follows: ellipses indicate speaker pauses and omissions from the transcript; numbers in parentheses indicate lengths of pauses; underlined portions of text (reproduced in italics for this publication) received emphasis from the speaker; words between two forward slashes are insertions or paraphrases to make the excerpt better comprehensible, especially without the context of the remaining transcript. In order to be able to refer to particular lines, we added line numbers to the transcript excerpts.

[23] Reinders Duit, Should energy be illustrated as something quasi-material?, Int. J. Sci. Educ. 9, 139 (1987).

[24] Gregg Swackhamer, http://modeling.asu.edu/modeling/ CognitiveResources-Energy.pdf.

[25] Rachael Lancor, Using metaphor theory to examine conceptions of energy in biology, chemistry, and physics, Sci. Educ., 1 (2012).

[26] Rachel E. Scherr, Hunter G. Close, Sarah B. McKagan, and Stamatis Vokos, Representing energy. I. Representing a substance ontology for energy, Phys. Rev. ST Phys. Educ. Res. 8, 020114 (2012).

[27] G. Bruno Schmid, Energy and its carriers, Phys. Educ. 17, 212 (1982).

[28] Eric Brewe, Energy as a substancelike quantity that flows: Theoretical considerations and pedagogical consequences, Phys. Rev. ST Phys. Educ. Res. 7, 020106 (2011).

[29] George Lakoff and Mark Johnson, Metaphors We Live By (The University of Chicago Press, Chicago, 2003), p. 276.

[30] Jochen Walz, Karl Ulrich, Helmut Port, Hans Christoph Wolf, Johann Wonner, and Franz Effenberger, Fulgides as switches for intramolecular energy transfer, Chem. Phys. Lett. 213, 321 (1993).

[31] Wolter H. Kaper and Martin J. Goedhart, 'Forms of energy,' an intermediary language on the road to thermodynamics? Part I, Int. J. Sci. Educ. 24, 81 (2002).

[32] Rosemary S. Russ, Rachel E. Scherr, David Hammer, and Jamie Mikeska, Recognizing mechanistic reasoning in student scientific inquiry: A framework for discourse analysis developed from philosophy of science, Sci. Educ. 92, 499 (2008).

[33] David Hammer, Student inquiry in a physics class discussion, Cognit. Instr. 13, 401 (1995).

[34] National Research Council (NRC), Science Education (National Academies Press, Washington, DC, 2011), p. 320. 